\title{
Structure and Corrosion Behavior of Nano-Crystalline Ni-P Alloy Containing Tungsten
}

\author{
Samar Refaat Gooda, Omyma Ramadan Mohammed Khalifa*, Aisha Kassab Abd El-Aziz, \\ Amany Hassan Marii
}

Chemistry Department, Faculty of Girls (Arts, Science and Education), Ain Shams University, Cairo, Egypt

\section{Email address:}

Omyma.khalifa@women.asu.edu.eg (O. R. M. Khalifa)

\section{To cite this article:}

Samar Refaat Gooda, Omyma Ramadan Mohammed Khalifa, Aisha Kassab Abd El-Aziz, Amany Hassan Marii. Structure and Corrosion Behavior of Nano-Crystalline Ni-P Alloy Containing Tungsten. American Journal of Physical Chemistry. Vol. 10, No. 1, 2021, pp. 1-5. doi: 10.11648/j.ajpc.20211001.11

Received: December 9, 2020; Accepted: December 24, 2020; Published: January 12, 2021

\begin{abstract}
The whole world is interested in the metal industry and its permanent development. One of these metals is carbon steel. Therefore, scientists tend to improve the properties of this metal, in this research we have improved the properties of carbon steel through electroless plating process of Ni-P and Ni-W-P alloys. In different industries, electroless nickel-phosphorus Ni-P and nickel-tungsten-phosphorus Ni-W-P deposits have been commonly used as engineering safety coatings. In our research, Ni-P and Ni-W-P were deposited on low carbon steel by using acid bath. To study the improvement of the properties of the coats, microstructure analysis investigated by thin film (XRD), coat's morphology by electron microscope scan (SEM), analyzing the coat by X-ray dispersive energy (EDX) and protection of corrosion of the coats were determined by potentiodynamic polarization measurements in artificial sea water $(3.5 \% \mathrm{NaCl}$ solution). The results indicated that the phases formed from the electroless coating give excellent corrosion resistance of low carbon steel and also indicated that the alloy formed in the presence of tungsten through the electroless bath give higher corrosion protection than that formed without it. As the concentration of tungstate increase in the bath, coat has higher corrosion protection i.e. Ni-W-P III $>$ Ni-W-P II $>$ Ni-W-P I $>$ Ni-P.
\end{abstract}

Keywords: Electroless, $\mathrm{Ni}-\mathrm{P}, \mathrm{Ni}-\mathrm{W}-\mathrm{P}$, Low Carbon Steel

\section{Introduction}

Electroless process is an autocatalytic technique that required action of the deposited metal and reduced by the electron obtained [1]. Also have advantages over electrolytic process such as uniform coating and non-conductive materials can be coated [2]. The resistance of corrosion and character of the crystalline deposit Ni-P could affected by the composition of the alloy and heat treatment [3]. Electroless plated Ni-P coatings are used in a wide variety of sectors, these have several attributes as nice wear, protection of corrosion and a strong degree of hardness [4-8]. Insertion of hard nanoparticles (e.g., C, Ti-Si- C, W, Ti-N, etc.) improve the properties of the alloy [9-19]. As the tungsten content increase the life time of the alloy increase, since Ni-W-P barrier have longer life time than Ni-P barrier [20]. Ni based coatings temperature resistance improved by adding tungsten that has high melting point. As tungsten increase the phosphorus decrease and make enhancement changes in nanocrystalline phase composition [21]. By heating the deposits of the binary and ternary alloys, the hardness increase [22]. At $400^{\circ} \mathrm{C}$ show crystallinity of $\mathrm{Ni}$ [23].

\section{Materials and Methods}

\subsection{Experimental Procedure}

The substrate material was low carbon steel for its low cost. The sample was $\left(2.5 \times 2 \times 0.1 \mathrm{~cm}^{3}\right)$ with chemical composition as shown in Table 1. 
Table 1. The analysis of low carbon steel (Wt percent).

\begin{tabular}{lllllll}
\hline Element & C & Mn & Si & P & Cr \\
wt $\%$ & 0.05 & 0.17 & 0.03 & 0.02 & 0.009 \\
Element & $\mathrm{Ni}$ & $\mathrm{Al}$ & Other & $\mathrm{Fe}$ & \\
$\mathrm{wt} \%$ & 0.01 & 0.04 & 0.025 & $\mathrm{Bal}$ & \\
\hline
\end{tabular}

The samples have been mechanically polished, cleaned with sodium carbonate, degreased in a degreasing alkaline solution, chemically etched in dilute $10 \% \mathrm{HCl}$ and washed down in running water and deionized water, dried and then hanged in the electroless bath.

\subsection{Bath Composition}

The electroless bath was included in $100 \mathrm{ml}$ glass container which was stored in a water bath at a steady temperature at $85^{\circ} \mathrm{C}$. All the deposits were plated for one hour at $\mathrm{pH}=4$. After deposition, the samples were again washed down in running water and deionized water, dried and kept for characterization. The coatings were deposited from the most stable bath containing, the source of $\mathrm{Ni}+2$ ions (nickel sulphate), reducing agent(sodium hypophosphite), complexing agent (Sodium acetate), lactic acid, propionic acid and the surfactant (sodium lauryl sulphate) then adding different concentration of sodium tungstate 20,40 and $60 \mathrm{~g} / \mathrm{l}$.

Table 2. Bath composition and operating conditions of acidic electroless $\mathrm{Ni}-\mathrm{P}$ and $\mathrm{Ni}-\mathrm{W}$-P coatings.

\begin{tabular}{llll}
\hline \multirow{2}{*}{ Chemical name } & Concentration $(\mathbf{g} / \mathbf{L})$ & & \\
\cline { 2 - 4 } & Ni-P & Ni-W-P 20g/L(I) & Ni-W-P 40g/L(II) \\
\hline Nickel sulphate & $30 \mathrm{~g} / \mathrm{L}$ & $30 \mathrm{~g} / \mathrm{L}$ & $30 \mathrm{~g} / \mathrm{L}$ \\
Sodium hypophosphite & $25 \mathrm{~g} / \mathrm{L}$ & $25 \mathrm{~g} / \mathrm{L}$ & $25 \mathrm{~g} / \mathrm{L}$ \\
Sodium acetate & $20 \mathrm{~g} / \mathrm{L}$ & $20 \mathrm{~g} / \mathrm{L}$ & $20 \mathrm{~g} / \mathrm{L}$ \\
Lactic acid & $10 \mathrm{~mL} / \mathrm{L}$ & $10 \mathrm{~mL} / \mathrm{L} / \mathrm{L}$ \\
Propionic acid & $10 \mathrm{~mL} / \mathrm{L}$ & $10 \mathrm{~mL} / \mathrm{L}$ & $10 \mathrm{~mL} / \mathrm{L}$ \\
Sodium lauryl sulphate & $0.3 \mathrm{~g} / \mathrm{L}$ & $0.3 \mathrm{~g} / \mathrm{L}$ & $10 \mathrm{~mL} / \mathrm{L}$ \\
Sodium tungstate & & $20 \mathrm{~g} / \mathrm{L}$ & $0.3 \mathrm{~g} / \mathrm{L}$ \\
Operating conditions: & & & $40 \mathrm{~g} / \mathrm{L}$ \\
PH & 4 & & $10 \mathrm{~mL} / \mathrm{L}$ \\
Temperature & $85^{\circ} \mathrm{C}$ & & $0.3 \mathrm{~g} / \mathrm{L}$ \\
Time of coating & $1 \mathrm{hr}$ & & $60 \mathrm{~g} / \mathrm{L}$ \\
\hline
\end{tabular}

\subsection{Thin Film (XRD), SEM and (EDX) Measurements}

A thin film (XRD) measurement was made in as deposited conditions and with heat treatment using an $\mathrm{X}$-ray diffractometer (Panalytical coX'pert PRO, Holland). Scanning electron microscope (SEM) (Quanta 250 FEG, Taiwan). And with x-ray fluorescence (XRF) energy dispersive analysis of model ARL 9400 (EDX).

\subsection{Electrochemical Study}

To find out the electrochemical polarization behavior of binary and ternary alloy coatings, potentiodynamic polarization studies were tested in $3.5 \% \mathrm{NaCl}$ solution at $30^{\circ} \mathrm{C}$ with scan rate of $0.01 \mathrm{~V} / \mathrm{sec}$ within a potential range of 0 to $250 \mathrm{mV}$. The polarization resistance (RP) was evaluated using the polarization resistance technique in the region of \pm $50 \mathrm{mv}$ with respect to Ecorr.

\section{Results and Discussion}

\subsection{Thin Film-(XRD)}

Figure 1 a-d shows X-ray diffraction pattern of the as deposited Ni-P and Ni-W-P deposits. The pattern of the diffraction of the as deposited coatings has only a single wide peak for all the deposits. The peak broading can be due to the deposit's amorphous existence. The reflections corresponding to
Nickel phosphide tetragonal Ni3P phase and nickel phosphide Rhombohedral Ni8P3 phase for Ni-P alloy. Nickel phosphide tetragonal Ni3P, three face centered cubic plane nickel (fcc), nickel tungstate phosphide NiW2P3 monoclinic and nickel phosphide rhombohedral Ni8P3 for Ni-W-P coatings.

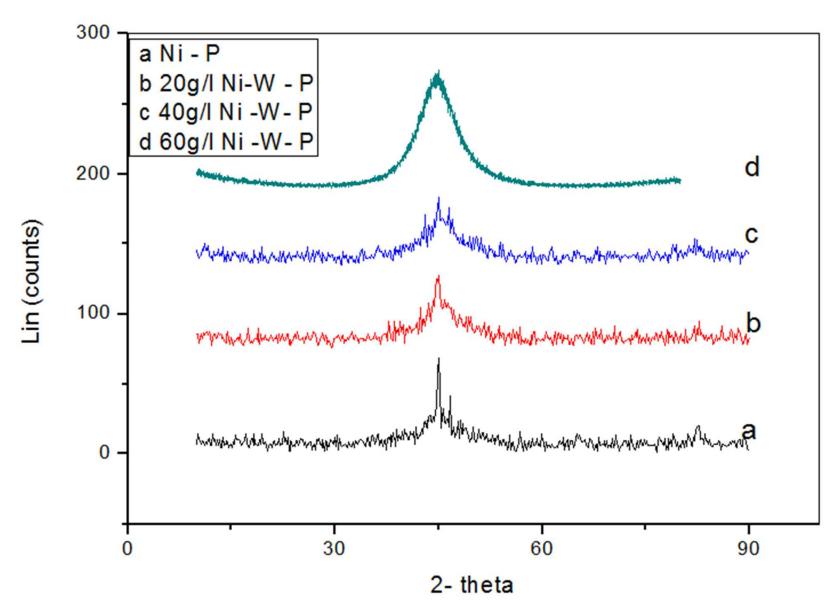

Figure 1. Thin film pattern of the as plated(a) Ni-P, (b) Ni-W-P (I), (c) Ni-W$P$ (II) and (d) Ni-W-P (III).

Figure 2 a-d shows the XRD pattern of binary and ternary alloys after annealing for 60 minutes at $400 \mathrm{oC}$. In all cases, the formation of face centered cubic plane nickel (fcc), and nickel phosphide tetragonal Ni3P phases are present beside nickel orthorhombic, NiW in case of the three ternary alloys. 


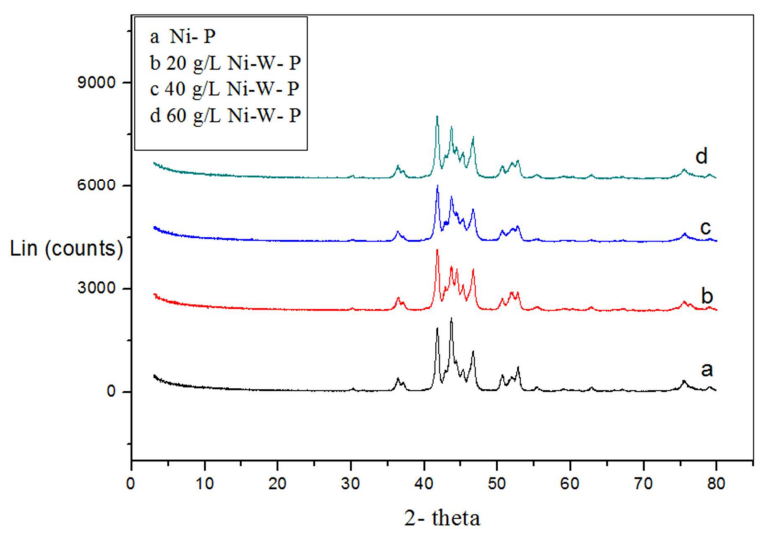

Figure 2. Thin film pattern of the electroless (a) Ni-P, (b) Ni-W-P I, (c) NiW-P II and (d) Ni-W-P III after heating.

There was a small rise in grain size for ternary alloys from Table 3. Ternary alloy coatings grain size increased attributed to the co-deposition of Win the nickel-tungsten-phosphorus deposits. The rise in grain size may be due to the presence of larger atoms of tungsten $(\mathrm{r}=2.02 \mathrm{Ao})$ in face centered cubic nickel matrix.
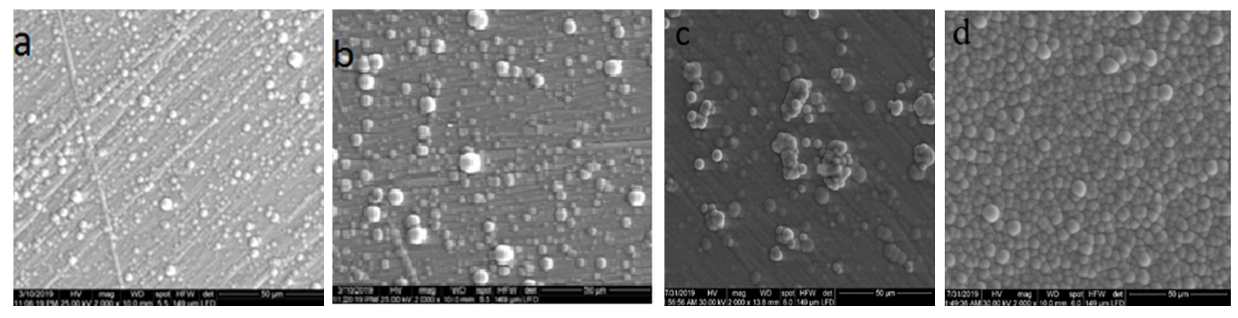

Figure 3. Surface morphology of as coated (a) Ni-P, (b) Ni-W-P (I), (c) Ni-W-P (II) and (d) Ni-W-P (III).

Nodular deposition in a coating depends on nucleation rate and the growth of the deposit. These SEM observations indicated obviously that the amount of sodium tungstate in plating bath will affect the nucleation rate and growth of deposit. Also we can notice that the addition of sodium tungstate make surface morphology fine, more compact grain and highly coalescence smooth deposit surface than that of
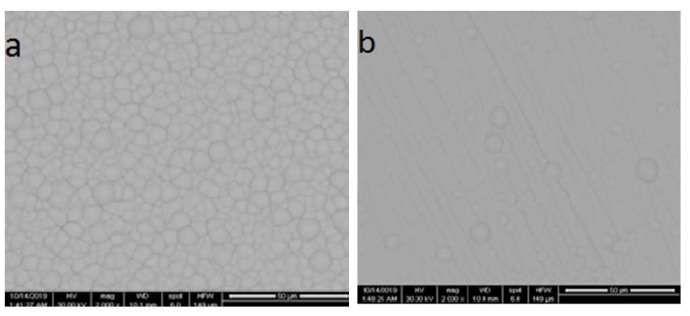

Figure 4. Scanning electron microscope of surface morphology after heat treatment (a) Ni-P, (b) Ni-W-P (I), (c) Ni-W-P (II) and (d) Ni-W-P (III).

\subsection{Dispersive Energy study of X-ray Fluorescence (EDX)}

Table 4. The element percentage of the constituent in Ni-P, Ni-W-P (I), Ni-W$P$ (II) and Ni-W-P (III) deposits.

\begin{tabular}{llll}
\hline \multirow{2}{*}{ Types of coating } & \multicolumn{3}{l}{ Weight percent (\%) } \\
\cline { 2 - 4 } & $\mathbf{N i}$ & $\mathbf{W}$ & $\mathbf{P}$ \\
\hline Ni-P & 88.66 & $\ldots \ldots \ldots$ & 11.66 \\
Ni-W-P (I) & 86.99 & 3.13 & 9.88 \\
Ni-W-P (II) & 87.58 & 5.02 & 6.40 \\
Ni-W-P (III) & 88.07 & 7.01 & 4.92 \\
\hline
\end{tabular}
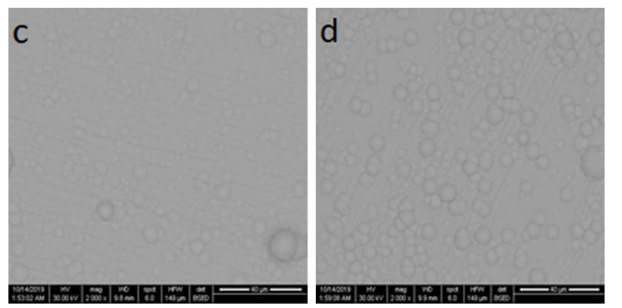

nickel phosphorous deposit. Annealing of binary and ternary alloys to $400^{\circ} \mathrm{C}$ for one hour, where the plating layer is finer and more coalescence due to the changes of the amorphous into crystalline alloy. The surface morphology of the heat treated coating binary and ternary alloys are shown in Figure 4 a-d respectively.

The analysis of the content of the as deposited electroless nickel coatings (EDX) are shown in table 4.

The decrease of phosphorus content as tungsten is added to electroless baths is due to produce of Ni-W-P films as shown from thin film XRD.

Competitive reaction between tungsten and phosphorus compounds can occur or the codeposition of phosphorus during deposition could be prevented by the formation of complex compounds. For all the plating baths, the nickel 
content was near 88 percent.

\subsection{Potentiodynamic Polarization Studies}

To understand the corrosion behavior of these coatings detail, potentiodynamic polarization studies were made in $3.5 \%$ $\mathrm{NaCl}$ solution at $30^{\circ} \mathrm{C}$. Figure 5 a-d shows the polarization curves for binary and ternary coatings in $3.5 \%$ sodium chloride solution and are compared with low carbon steel substrate (straight line). The parameters of electrochemical corrosion obtained from Tafel curves are tabulated in table 5. It's clearly seen from the table that the corrosion current density value for all the coatings in $3.5 \% \mathrm{NaCl}$ solution is from $15.84 \times 103$ to $10.939 \times 103 \mathrm{nA} / \mathrm{cm} 2$. For mild steel substrate $(15.84 \times 103 \mathrm{nA} / \mathrm{cm} 2)$ a higher corrosion current density value is obtained. The corrosion rate (MPY) calculated for these coatings also show similar trend as shown in the table 5 .

Table 5. The corrosion kinetic parameters for different tungstate concentration in $3.5 \% \mathrm{NaCl}$ solution.

\begin{tabular}{|c|c|c|c|c|c|c|}
\hline Type of coat & $E_{\text {corr }}$ (volt) & $I_{\text {corr }}\left(\mathrm{nA} / \mathrm{cm}^{2}\right)$ & $\mathrm{C}_{\mathrm{R}}$ (MPY) & $\mathbf{B a}$ & Bc & Rp (ohm) \\
\hline substrate & -0.714 & $15.84 \times 10^{3}$ & 186.402 & 0.1 & 0.6 & 2352 \\
\hline Ni-P & -0.531 & $10.93 \times 10^{3}$ & 128.728 & 0.11 & 0.61 & 3707 \\
\hline Ni-W-P (I) & -0.269 & $6.91 \times 10^{3}$ & 81.406 & 0.12 & 0.63 & 6342 \\
\hline Ni-W-P (II) & -0.216 & $4.78 \times 10^{3}$ & 56.324 & 0.17 & 0.69 & 12406 \\
\hline Ni-W-P (III) & -0.198 & $3.01 \times 10^{3}$ & 35.537 & 0.21 & 0.73 & 23556 \\
\hline
\end{tabular}

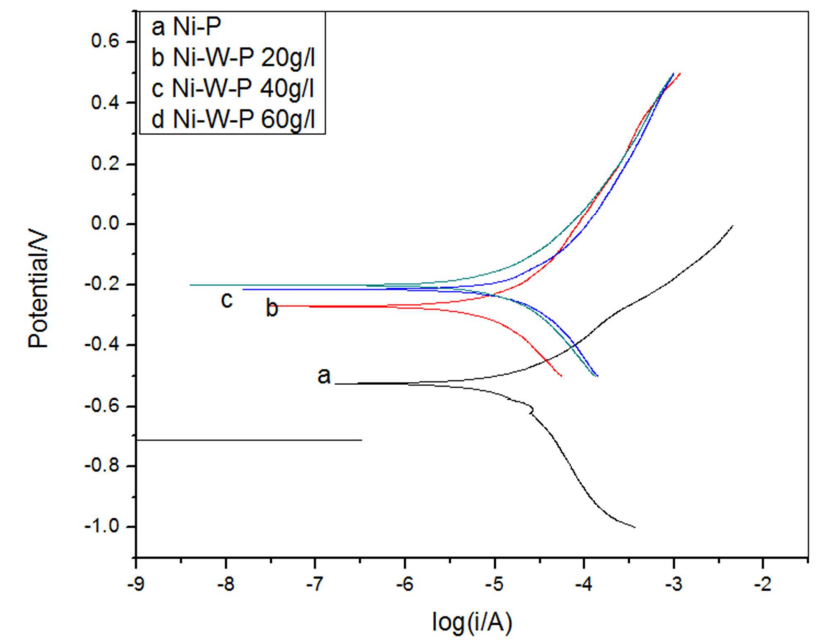

Figure 5. Potentiodynamic polarization curves of as deposited electroless (a) $\mathrm{Ni}-\mathrm{P}$, (b) Ni-W-P I, (c) Ni-W-P II and (d) Ni-W-P III in $3.5 \% \mathrm{NaCl}$ solution.

The preferential dissolution of nickel leading to the enrichment of phosphorous on the surface layer is evident from literature on Ni-P coatings. This enriched phosphorous interacts with water to form a coating of adsorbed hypophosphite anions $\left(\mathrm{H}_{2} \mathrm{PO}_{2}^{-}\right)$, which in turn blocks water supply to the electrode surface preventing nickel hydration which is known to be the first step in the formation of either $\mathrm{Ni}^{+2}$ species or a passive nickel film. So, the more resistant to corrosion obtained for electroless Ni-P and poly alloy coating because of the enrichment of phosphorous on the electrode surface. The protection of corrosion follow the sequence NiW-P III $<$ Ni-W-P II $<$ Ni-W-P I $<$ Ni-P.

\section{Conclusion}

Electroless binary and ternary Ni-P, Ni-W-P I, Ni-W-P II and Ni-W-P III films were prepared using acidic bath. Inclusion of an alloying element influenced the composition of the deposit, XRD results revealed that all the as plated deposits had a single wide peak of Ni III. The grain size of the as deposited Ni-P, Ni-W-P I, Ni-W-P II and Ni-W-P III were 3, 3.6, 6.1, and 14 respectively. As plated deposits exhibited nodular appearance. Presence of tungsten improved the corrosion resistance in $3.5 \% \mathrm{NaCl}$ solution. Annealing binary and ternary alloys show nodular structure also and sharp peaks of X-Ray diffraction.

\section{References}

[1] J. Sudagar, J. Lian, W. Sha, "Electroless nickel alloy composite and nano coatings - A critical review, Journal of Alloys and Compounds, vol. 571, 2013, pp. 183-204.

[2] S. Cheon, S. Park, Y. Rhym, D. Kim, J. Lee, "'The effect of bath conditions on the electroless nickel plating on the porous carbon substrate, Current Applied Physics, vol. 11, 2011, pp. 790-793.

[3] T. Rabizadeh, S. R. Allahkaram, A. Zarebidaki, An investigation on effects of heat treatment on corrosion properties of Ni-P electroless nano-coatings, Materials and Design, vol. 31, 2010, pp. 3174-3179.

[4] P. Sahoo, S. K. Das, Tribology of electroless nickel coating - a review, Mater, vol. 32, 2011, pp. 1760-1775.

[5] C. Wang, Z. Farhat, G. Jarjoura, M. K. Hassan, A. M. Abdullah, Indentation and erosion behavior of electroless Ni-P coating on pipeline steel, Wear, pp. 376-377, 2017, pp. 16301639 .

[6] C. Wang, Z. Farhat, G. Jarjoura, M. K. Hassan, A. M. Abdullah, E. M. Fayyad, Investigation of fracture behavior of annealed electroless Ni-P coating on pipeline steel using acoustic emission methodology, Surf. Coat. Technol., Issu. 326, 2017, pp. 336-342.

[7] R. Gan, D. Wang, Z.-H. Xie, L. He, Improving surface characteristic and corrosion inhibition of coating on $\mathrm{Mg}$ alloy by trace stannous (II) chloride, Corros. Sci. Issu. 137, 2017, pp. 147-157.

[8] J. Wasserbauer, M. Buchtík, J. Tkacz, S. Fintová, J. Minda and L. Doskocil, Improvement of AZ91 Alloy Corrosion Properties by Duplex NI-P Coating Deposition, Materials vol. 13, 2020, pp. 135. 
[9] J. N. Balaraju, Kalavati, K. S. Rajam, Electroless ternary NiW-P alloys containing micron size $\mathrm{Al}_{2} \mathrm{O}_{3}$ particles, Surf. Coat. Technol. vol. 205, 2010, pp. 575-581.

[10] S. Afroukhteh, C. Dehghanian, M. Emamy, Preparation of the $\mathrm{Ni}-\mathrm{P}$ composite coating co-deposited by nanoTiC particles and evaluation of its corrosion property, Appl. Surf. Sci. Issu. 258, vol. 7, 2012, pp. 2597-2601.

[11] C. Wang, Z. Farhat, G. Jarjoura, M. K. Hassan, A. M. Abdullah, Indentation and bending behavior of electroless NiP-Ti composite coatings on pipeline steel, Surf. Coat. Technol. vol. 334, 2018 pp. 243-252.

[12] L. Masry, G. Jarjoura, Z. Farhat, E. M. Fayyad, A. M. Abdullah, M. K. H. Mohamed, Development of novel corrosion resistant electroless Ni-P composite coatings for pipeline steel, IJESRT. Vol. 7, 2018, pp. 122-134.

[13] Z.-H. Xie, D. Li, Z. Skeete, A. Sharma, C.-J. Zhong, Nanocontainer-enhanced self-healing for corrosion-resistant Ni coating on Mg alloy, ACS Appl. Mater. Interfaces vol. 9, Issu 41, 2017, pp. 36247-36260.

[14] Z.-H. Xie, S. Shan, Nano-containers enhanced self-healing Ni coating for corrosion protection of $\mathrm{Mg}$ alloy, J. Mater. Sci. vol. 53, 2018, pp. 3744-3755.

[15] E. M. Fayyada, A. M. Abdullah, A. M. A. Mohamed, G. Jarjoura, Z. Farhat, M. K. Hassan, Effect of electroless bath composition on the mechanical, chemical, and electrochemical properties of new Ni-P- $\mathrm{C}_{3} \mathrm{~N}_{4}$ nanocomposite coatings, Surface \& Coatings Technology, Issu 362, 2019, pp. 239-251.

[16] Hu Y, Yang L, Shi C, Tang W. Microstructural evolution and phase transformation kinetics of pulse-electroplated $\mathrm{Ni}-\mathrm{Cu}-\mathrm{P}$ alloy film during annealing. Materials Chemistry and Physics. vol. 141,2013 , pp. $944-950$.

[17] Narayanan TSNS, Selvakumar S, Stephen A. Electroless NiCo-P ternary alloy deposits: preparation and characteristics. Surface and Coatings Technology. vol. 172, 2003, pp. 298-307.

[18] Zhang WX, Jiang ZH, Li GY, Jiang Q, Lian JS. Electroless Ni-Sn-P coating on AZ91D magnesium alloy and its corrosion resistance. Surface and Coatings Technology. Issu. 202, vol. 12, 2008, pp. 2570-2576.

[19] Balaraju JN, Chembath M. Electroless ternary Ni-Ce-P coatings: Preparation and characterisation. Applied Surface Science, vol. 24, Issu 258, 2012, pp. 9692-9700.

[20] J. N. Balaraju, Kalavati, N. T. Manikandanath, V. K. William, Phase transformation behavior of nanocrystalline Ni-W-P alloys containing various $\mathrm{W}$ and $\mathrm{P}$ contents, Surface \& Coatings Technology, vol. 206, 2012, pp. 2682-2689,.

[21] C. Yanhai, C. Shuai, H. Qingqiang, H. Dongtai, H. Zhengtong, Effect of Tungsten Addition on the Anti-fouling Property of the Electroless Ni-W-P Deposits, Rare Metal Materials and Engineering, Issu. 45, vol. 8, 2016, pp. 1931-1937.

[22] Oliveira, Mara, Correa, Olandir, Ett, Bardia, Sayeg, Lima, Nelson, Antunes, Renato, Influence of the Tungsten Content on Surface Properties of Electroless Ni-W-P Coatings. Materials Research. Issu. 21. vol. 10. 2017, pp. 5373.

[23] Shirya, Andrey \& Woodcutters, A\&C. C. Adilova \& Aliyev, A. Electrochemical deposition of Ni-W-P alloy (Electrodeposition of Ni-W-P alloy). Vol 25, Issu. 51-57. 2020, pp. 95. 1-7. 